\title{
A current review of folate receptor alpha as a potential tumor target in non-small-cell lung cancer
}

This article was published in the following Dove Press journal:

Drug Design, Development and Therapy

3I August 2015

Number of times this article has been viewed

\section{Huan Shi* \\ Jun Guo* \\ Changzheng Li \\ Zhehai Wang}

Department of Oncology, Shandong Cancer Hospital and Institute, Jinan, Shandong, People's Republic of China

*These authors contributed equally to this work
Correspondence: Zhehai Wang Department of Oncology, Shandong Cancer Hospital and Institute, No 440 Jiyan Road, Jinan 250II7, Shandong, People's Republic of China $\mathrm{Tel} / \mathrm{fax}+86$ 53l 6762 633। Email wzhai8778@yahoo.com

\begin{abstract}
Lung cancer remains the leading common cause of cancer-related death, with non-small-cell lung cancer (NSCLC) accounting for $80 \%$ of all cases. To date, platinum-based doublet chemotherapy is the cornerstone of first-line therapy. However, these agents have limited use in patients who have relapsed and have metastatic disease. Therefore, novel strategies are required to improve the clinical outcome. Folate receptor alpha (FRA) is overexpressed in the majority of NSCLC, particularly in lung adenocarcinomas. FRA is largely absent from normal tissue, making it an attractive therapeutic target. In this review, we discuss FRA expression in NSCLC, conjugated FRA agents, monoclonal antibody, and FRA-specific T-cell-based therapeutic strategies aiming to improve the cure rate of FRA-expressing NSCLC.
\end{abstract}

Keywords: folate receptor alpha, lung cancer, immunotherapy

\section{Introduction}

Lung cancer represents the leading cause of cancer death worldwide. ${ }^{1}$ Non-small-cell lung cancer (NSCLC) constitutes $\sim 80 \%$ of lung cancers. The most common histological subtypes of NSCLC include adenocarcinoma (AC), squamous cell carcinoma (SCC), and large-cell carcinoma. Metastatic disease is observed in $\sim 40 \%$ of newly diagnosed patients with NSCLC, and the majority of the remainder will eventually develop metastases. ${ }^{2}$ Despite the recent advances in surgery, radiotherapy, chemotherapeutic agents, and novel molecular targeted drugs in the past decades, the prognosis of NSCLC is still poor, and the overall 5-year survival rate is $17.1 \%{ }^{3}$ It is essential to find novel therapeutic approaches to improve the prognosis of NSCLC. An improved understanding of the immune system along with the discovery of tumor-associated antigens (TAAs) has made it possible to design various immunotherapy strategies for lung cancer. ${ }^{4}$ Folate receptor alpha (FRA), a glycosylphosphatidylinositol-anchored cell surface glycoprotein, is overexpressed on the surface of various tumor types, including pancreatic, prostate, head and neck, breast, and ovarian cancer (OC), mesothelioma, as well as NSCLC. ${ }^{5-13}$ Folic acid (an essential B vitamin) is necessary for proper cell growth and one-carbon transfer processes mediated by numerous enzymes that are involved in DNA synthesis. ${ }^{14}$ FRA binds folic acid with high affinity and mediates its intracellular transport via receptor-mediated endocytosis. ${ }^{15}$ The expression of FRA allows epithelial tumor cells to proliferate suggesting that FRA is an acquired tumor cell proliferation, tumor biology, and patient prognosis marker. ${ }^{6,12,16-18}$ Several studies have suggested that levels of FRA expression are associated with tumor stage and survival in lung AC. ${ }^{8,13}$ FRA has a much more limited normal tissue distribution, with measurable expression restricted largely to the apical surfaces of the epithelial 
tissue, predominantly in the kidney, lung, and choroid plexus, where it is inaccessible to the drugs in circulation. ${ }^{19,20}$ Due to its limited expression and restricted distribution pattern in normal tissue, FRA is the most widely studied member of folate receptor family and is an attractive TAA for cancer immunotherapy. ${ }^{21}$

To date, various strategies for targeting FRA-expressing cancers have been developed. In this review, we provide an overview of the expression of FRA in NSCLC. We further discuss the potential treatment approaches for FRAexpressing lung cancer, including conjugated FRA agents, an FRA-specific monoclonal antibody (mAb) - farletuzumab, and novel chimeric antigen receptor (CAR)-based T-cell therapy for NSCLC.

\section{FRA in NSCLC}

High level of FRA expression in NSCLC was well demonstrated by various groups..$^{8,9,22,23}$ In the largest of these studies, FRA expression was examined by immunohistochemistry (IHC) analysis in 320 surgically resected NSCLC tissue specimens comprising 202 ACs and 118 SCCs. ${ }^{9}$ ACs were more likely to express FRA than SCCs, and the mean expression scores were significantly higher in ACs than in SCCs at the membrane and cytoplasmic localizations. Tumors from never-smokers were significantly more likely to express cytoplasmic FRA than those from smokers. Further, advanced tumors demonstrated similar levels of FRA expression compared with surgically resected tumors. Moreover, epidermal growth factor receptor (EGFR)-mutant ACs demonstrated significantly higher expression scores for membrane FRA than wild-type tumors. Therapeutic agents targeting the FRA or EGFR are approved by the US Food and Drug Administration or are in clinical development. Christoph et $\mathrm{al}^{24}$ found that 47 patients $(29 \%)$ had high expression of both of the receptors and could be candidates for combined targeted therapy. Another study ${ }^{25}$ also supports that a significantly higher proportion of ACs were positive for FRA when compared to other histologies $(P<0.001)$ and in females versus males $(P=0.003)$, utilizing AQUA $^{\circledR}$ technology (Genoptix Medical Laboratory, Carlsbad, CA, USA), an automated fluorescence IHC-based method that provides continuous protein expression scores in tissue. However, Cagle et $\mathrm{al}^{22}$ showed that both lung ACs and SCCs expressed relatively high levels of FRA in the malignant cells. In addition, FRApositive circulating tumor cells were detected in patients with NSCLC, even in early-stage tumors. ${ }^{26}$ Taken together, all these results suggest that FRA is a highly promising target, and a greater percentage of lung cancer patients may benefit from FRA-based therapies.
In contrast from studies in breast cancer, OC, and other epithelial cancers, ${ }^{18,27,28}$ higher FRA expression exerts a favorable influence in early-stage NSCLC, ${ }^{8,13}$ suggesting that FRA plays a contrasting role with respect to tumor development and/or progression in NSCLC. The impact of FRA overexpression on prognosis of NSCLC is not well understood, and the mechanisms by which this may occur need further investigation.

\section{FRA-based therapy for NSCLC Folate acid conjugates}

Targeting of FRA-positive tumor cells in vitro and in vivo has been exemplified using folic acid conjugates with a variety of therapeutic probes (Figure 1A). For this approach, folate can be linked to chemotherapeutic agents, nanoparticles, drug-loaded liposomes, and oligonucleotides. ${ }^{29,30}$ The FRA can actively internalize bound folate-drug conjugates via the natural process of endocytosis (Figure 1A and D). ${ }^{31}$ Because there is limited distribution of FRA on normal tissue and folate-bound drug is not active, folate conjugates can achieve cancer-specific drug delivery with minimal toxicity.

Among those, the most advanced approach is the concept of using folic acid-targeted chemotherapeutics. EC145 (also known as vintafolide or MK-8109) is a novel folate-conjugated vinca alkaloid (desacetylvinblastine monohydrazide; DAVLBH) $)^{32}$ that binds to the FRA with high affinity. EC145 produces marked antitumor activity specifically against FRA-expressing tumor xenografts without significant toxicity, ${ }^{33}$ thereby prompting the clinical studies. Early clinical results ${ }^{34}$ suggest that EC145 appeared well tolerated, without remarkable toxicity observed in vinca alkaloids. Further results of a multicenter trial ${ }^{35}$ in a highly refractory population with advanced NSCLC indicated the antitumor activity of EC145, and in that, a clinical benefit response of $26 \%$ was obtained. The median progression-free survival (PFS) and overall survival were 7.4 weeks and 42.9 weeks, respectively. Further exploratory analysis demonstrated that patients who are $\operatorname{FRA}(2+)$ have superior clinical benefit response compared with those who are FRA $(1+)(50 \%$ versus $14.3 \% ; P=0.10)$ based on EC20 uptake. EC20 is a peptide derivative of folic acid and was designed to efficiently coordinate ${ }^{99 \mathrm{~m}} \mathrm{Tc}$. This new chelate was found to bind FRA-positive tumor cells in both a timeand concentration-dependent manner with very high affinity. EC20 uptake may represent a positive prognostic marker, and further development of EC145 and other FRA-targeted therapeutics for the treatment of AC of the lung should be explored. There were no drug-related grade 4 toxicities reported. The most common drug-related adverse events 
A

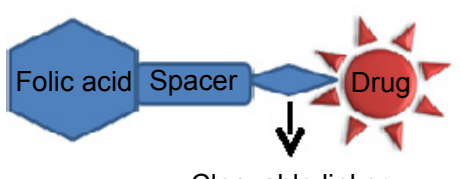

Cleavable linker
B

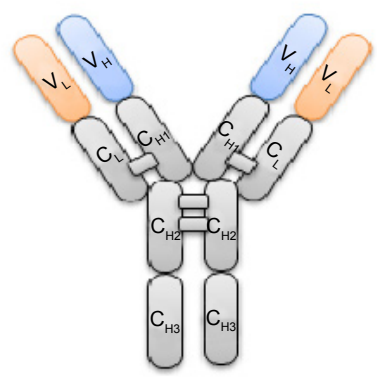

C

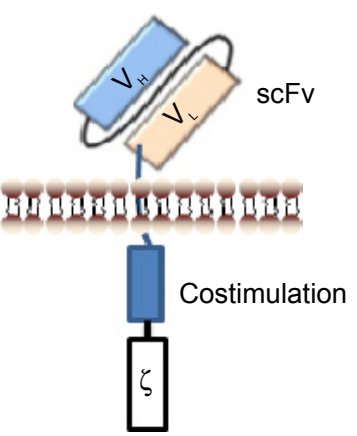

D

(1) Folate acid conjugates

(2) Antibody

\section{(3) CAR T-cell}

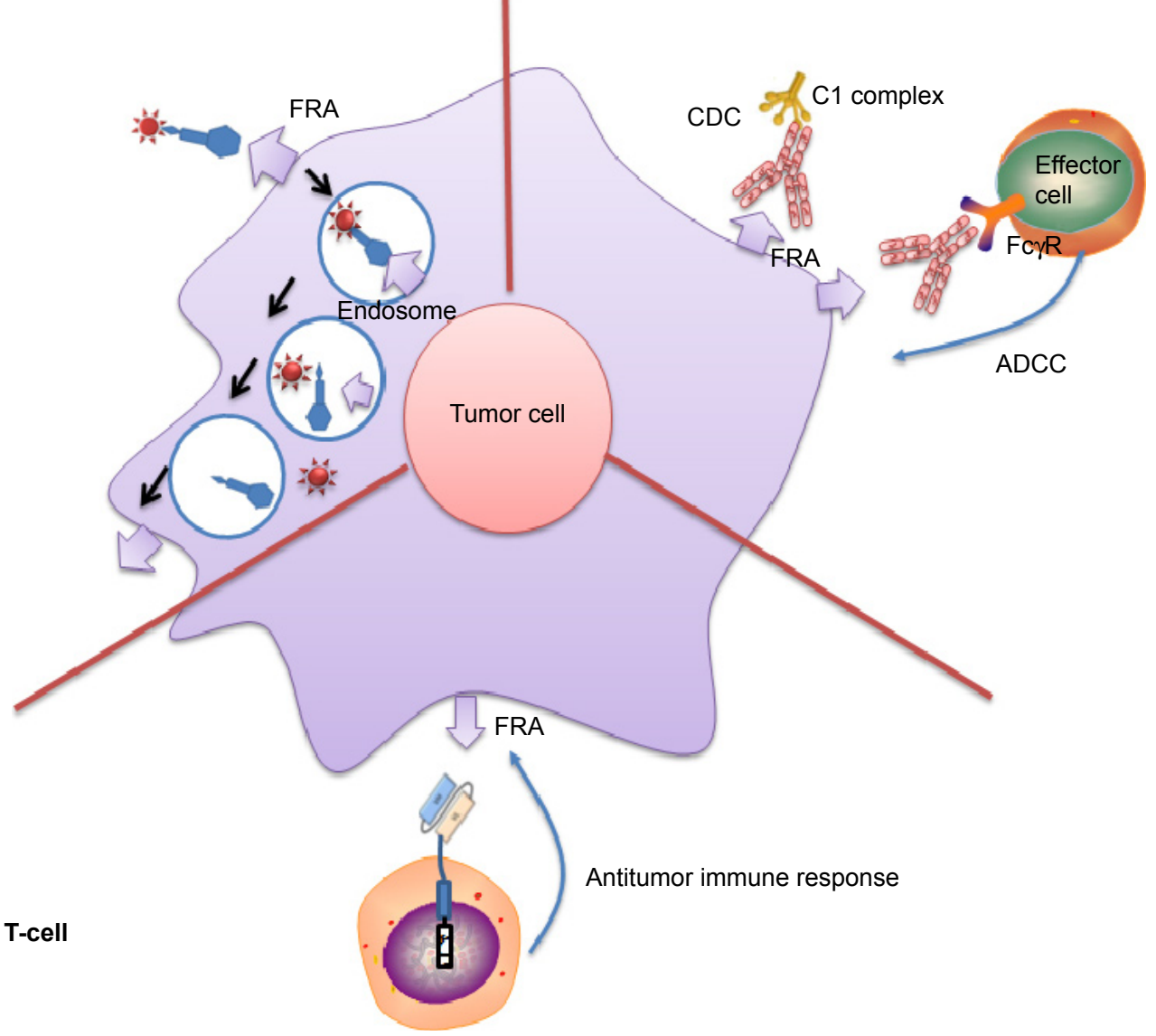

Figure I Schematic diagram of three therapeutic strategies in FRA-expressing NSCLC cells.

Notes: (A) A modular diagram of a folate-drug conjugate composed of folic acid, spacer, cleavable linker, and an active agent. (B) FRA-specific mAb. (C) Costimulated FRA-specific CAR. (D) Possible mechanisms of action of different therapeutic strategies targeting FRA: (I) Folate-mediated delivery of therapeutic agents to FRA-positive cancer cells by receptor-mediated endocytosis. The active drug is cleaved inside endosome, and then escapes endosome and exerts activity on cells. (2) Antibody can cause cell lysis through activation of CDC and interact with Fc receptors on effector cells to engage in ADCC. (3) Costimulated CARs are designed to allow full T-cell activation, recognition, and killing of tumor cells.

Abbreviations: FRA, folate receptor alpha; NSCLC, non-small-cell lung cancer; mAb, monoclonal antibody; CAR, chimeric antigen receptor; CDC, complement-dependent cytotoxicity; ADCC, antibody-dependent cellular cytotoxicity; ScFv, single-chain variable fragment.

(AEs) were fatigue, peripheral neuropathy, and constipation, primarily grade $1 / 2$ in severity. Further, a randomized Phase II trial comparing the activity of EC145 and EC145 plus docetaxel with docetaxel alone in higher FRA expression tumors $(2+)$ has been activated (ClinicalTrials.gov Identifier: NCT01577654).

A wide range of other therapeutic folate conjugates could conceivably be constructed given their ability to deliver 
therapeutic agents via endocytosis. The folate-targeted therapeutic agents include a highly immunogenic hapten, ${ }^{21}$ an epothilone, or a dual-warhead folate conjugate in the same molecule. ${ }^{36}$ Patients were first immunized against a hapten to stimulate an anti-fluorescein isothiocyanate (FITC) antibody $(\mathrm{Ab})$ response. EC17 (folate-FITC conjugate) redirects anti-FITC-conjugated hapten $\mathrm{Ab}$ produced by the patients to FRA-expressing tumor cells, which leads to the removal of the Ab-coated tumor cells; the safety of this strategy was demonstrated in renal cancer and OC patients. ${ }^{37}$ Epofolate (BMS-753493) is a folate conjugate of a microtubulestabilizing agent epothilone A. Currently, Epofolate is undergoing Phase I/II clinical trial (ClinicalTrials.gov Identifier: NCT00546247 and NCT00550017) sponsored by Bristol-Myers Squibb in advanced cancers. EC0225, a folate conjugated to both vinca alkaloid and mitomycin, has completed a Phase I trial (ClinicalTrials.gov Identifier: NCT00441870). The high level of FRA expression in lung cancers argues that lung cancers could be a good indication of various conjugated FRA agents.

\section{FRA-specific mAbs}

The use of mAbs (Figure 1B and D) therapy can selectively target the FRA-expressing tumors, and thus offer potential benefits such as avoiding the cytotoxic toxicity in normal tissue caused by traditional chemotherapeutic agents.

IHC studies using an FRA-binding murine mAb, LK26, showed highly restricted distribution of FRA in normal tissues but widespread expression on cancer cells, including OC and renal cancer. ${ }^{38}$ Farletuzumab (MORAb-003) is a humanized immunoglobulin G subtype 1 kappa mAb against FRA and was developed by Morphotek, Inc. Farletuzumab exhibited an affinity similar to the original LK26 Ab $(\sim 2 \mathrm{nM})$ and a tissue-binding profile consistent with tissue distribution of $\mathrm{FRA}^{38}$ after the optimization process using a whole-cell genetic evolution platform. ${ }^{39}$ Rather than blocking FRA-mediated folate transport, farletuzumab shows tumor cytotoxicity mediated by Ab-dependent cellular cytotoxicity and complement-dependent cytotoxicity. ${ }^{40,41}$ Farletuzumab has also been shown to inhibit the interaction between Lyn kinase and membrane signaling complexes, thus reducing the growth advantage of FRA-overexpressing cancer cells. ${ }^{45}$ More recently, Wen et $\mathrm{al}^{42}$ described a previously unrecognized mechanism that farletuzumab regulated an array of autophagy-related genes and farletuzumab treatment has potential for inhibiting tumor cell growth by sustaining late-stage autophagy. This study also showed that the level of FRA expression was correlated with the extent of farletuzumab therapeutic effect and farletuzumab significantly augmented the antitumor effect of docetaxel through an autophagy-associated mechanism.

The above encouraging preclinical studies led to the development of a Phase I/II clinical trial ${ }^{43,44}$ with farletuzumab, which demonstrated the safety and tolerability of farletuzumab in the treatment of heavily pretreated epithelial ovarian cancer (EOC) patients. No serious or severe AEs or treatment-related myelotoxicity or neurotoxicity was reported. These results provided a rationale for the beginning of a Phase III, three-arm randomized, placebo-controlled, double-blind clinical trial investigating farletuzumab in combination with taxane and carboplatin in 1,100 patients with platinum-sensitive EOC at first relapse (ClinicalTrials.gov Identifier: NCT00849667). Carboplatin and paclitaxel at standard dosages were administered with either farletuzumab at two different dose levels, $1.25 \mathrm{mg} / \mathrm{kg}$ (arm 1) and $2.5 \mathrm{mg} / \mathrm{kg}$ (arm 2), or placebo (arm 3). The length of first remission was similar among the three arms of treatment. The most common treatment-related AEs were associated with the chemotherapy agents. Median PFS was 9.5 months in arm 1, 9.7 months in arm 2, and 9.0 months in the placebo group (arm 3) with no statistically significant difference between arms. Therefore, the study failed to meet its primary endpoint of improved PFS; however, higher doses of farletuzumab may improve the PFS. More recently, Sasaki et $\mathrm{al}^{45}$ conducted a Phase I trial of farletuzumab in Japanese patients with OC and gastric cancer (GC). This trial showed long-term disease stabilization for 20 months and 25 months in one patient with $\mathrm{GC}\left(400 \mathrm{mg} / \mathrm{m}^{2}\right)$ and one patient with clear cell OC $\left(100 \mathrm{mg} / \mathrm{m}^{2}\right)$, respectively. But no objective response was recorded. Major AEs, including nausea and decreased appetite (five patients each, 31.3\%), headache (seven patients, 43.8\%), and grade 1/2 infusionrelated reaction (15 patients, 93.8\%), were observed. Neither dose-limiting toxicities nor grade $3 / 4$ toxicities were reported, and farletuzumab was generally well tolerated in Japanese patients receiving a larger dose $\left(400 \mathrm{mg} / \mathrm{m}^{2}\right)$.

Farletuzumab is also evaluated in NSCLC based on preclinical data and safety profile in combination with carboplatin/taxane regimen from OC. A Phase II, double blind, placebo-controlled multicenter study (ClinicalTrials.gov Identifier: NCT01218516), evaluating farletuzumab in 130 patients with FRA-expressing metastatic lung ACs, has been completed. In this study, FRA expression is confirmed by IHC, and eligible patients have tumors with $1+$ or greater membranous staining. Patients were randomized to receive farletuzumab or placebo in a 1:1 ratio with six cycles of one of three combinations: carboplatin and 
pemetrexed, cisplatin and pemetrexed, or carboplatin and paclitaxel. After standard pre-medication with acetaminophen, farletuzumab $(7.5 \mathrm{mg} / \mathrm{kg})$ or placebo was administered intravenously on cycle 1, week 1 and cycle 1, week 2 (loading dose) followed by once in 3 weeks from cycles 2 to 6 (induction therapy). Patients who experience clinical benefit from induction therapy receive maintenance farletuzumab or placebo every 3 weeks until disease progression. The further exploratory studies evaluate the correlation between tissue FRA and serum and urine FRA and their role as surrogate markers for treatment response and survival. The primary objective of this study is evaluation of 3-month PFS with the addition of farletuzumab to first-line platinum-based chemotherapy regimens. However, the results have not been posted.

Combining chemotherapy with farletuzumab may be an effective way to treat NSCLC. Pemetrexed is an antifolate chemotherapy drug that has been approved for firstline treatment of patients with advanced nonsquamous, NSCLC in combination with cisplatin and as a single agent for relapsed or chemotherapy-refractory NSCLC after platinum-containing chemotherapy. ${ }^{46}$ Pemetrexed inhibits both purine and pyrimidine syntheses by blocking three key metabolic enzymes involved in DNA synthesis: dihydrofolate reductase, thymidylate synthase, and glycinamide ribonucleotide formyl transferase. Multiple studies have demonstrated that pemetrexed is effective as first-line ${ }^{47,48}$ and maintenance therapy of NSCLC. ${ }^{49,50}$ Subgroup analyses indicated that pemetrexed is mainly effective and superior to other regimens in non-SCCs. Farletuzumab combined with pemetrexed may produce synergic effect, but it could also increase AEs. A safety and efficacy study of farletuzumab in combination with platinum-based pemetrexed or paclitaxel chemotherapy against placebo plus the same regimens was recently completed (ClinicalTrials.gov Identifier: NCT01218516).

\section{FRA-specific T-cells}

Currently, there are various forms of natural tumor-reactive immune cells generated for lung cancer in clinical trials, such as tumor-infiltrating lymphocytes, cytokine-induced killer cells, $\gamma \delta \mathrm{T}$-cells, and natural killer cells. ${ }^{51} \mathrm{~T}$-cell therapy has emerged as an exciting powerful approach for cancer immunotherapy. ${ }^{52}$ Adoptive cellular therapy involves the ex vivo identification and expansion of autologous T-cells with antitumor activity, which are then adoptively transferred back into cancer patients. ${ }^{52,53}$ Human peripheral blood T-cells can be engineered to express an FRA-specific CAR, which typically comprises an extracellular single-chain variable fragment derived from an mAb specific for FRA, a spacer domain that provides flexibility and optimizes T-cell and target cell engagement, a transmembrane domain, and signaling modules that trigger $\mathrm{T}$-cell activation and costimulation (Figure 1C) ${ }^{54,55}$ Once expressed on T-cell surface, FRA-specific CAR-modified T-cells can recognize FRA on the tumor cell surface in a non-major histocompatibility complexdependent manner and induce an antitumor immune response (Figure 1C and D). Furthermore, CAR-modified T-cells actively and specifically home to tumor sites and persist as memory cells in vivo. ${ }^{53}$ Therefore, CAR T-cells may be more effective than $\mathrm{mAbs}$ in generating durable tumor responses, and CAR T-cells have been proposed as the next generation of immunotherapeutic "living drugs". 53,56,57

In a Phase I clinical trial, ${ }^{58}$ transfer of FRA CAR T-cells for the treatment of metastatic OC failed to induce tumor regression due to the poor persistence of "first-generation" CAR T-cells in vivo. According to the two-signaling model for T-cell activation, costimulation is required in addition to the antigen-specific signal from its antigen receptors. Investigators have constructed and tested "second-generation" CARs containing costimulatory cytoplasmic signaling domains derived from the T-cell costimulatory molecules. Previous studies ${ }^{54,55}$ showed that CD137(4-1BB)-, CD28-, or CD27-costimulated FRA CAR T-cells could overcome the issues of engineered T-cell persistence and tumor localization that limit the FRA CAR T-cell targeting strategy to provide potent antitumor activity in vivo.

FRA CAR T-cell therapy can also potentially be used to treat the majority of lung cancers. However, targeting FRA expressing on lung cancer may induce severe toxicity such as "cytokine storm" mediated by "on-target" efficacy (antitumor effects). Previously, deadly toxicity was reported maybe due to the "on-target" effect - even the low levels of TAA of ERBB2 on normal lung epithelia were recognized by CAR T-cells. ${ }^{59}$ Thus, CAR T-cell-targeting TAAs expressed on vital organs will need to be used with caution.

There are a number of strategies that can be employed to improve the safety of FRA CAR T-cell therapy. First and most importantly, a conservative dose-escalation strategy for CAR T-cell therapy infusion should be evaluated in clinical application, which may prevent the severe toxicities. ${ }^{60}$ Second, generation of transient CAR T-cells may be a safer approach. For example, developing FRA-specific RNA encoding CAR T-cells may be safe, and the toxicity would be expected to abate rapidly, due to the transient nature of CAR expression on the T-cells. ${ }^{61}$ RNA CAR T-cells could mediate antitumor activity in patients with advanced solid tumors. ${ }^{62}$ Alternatively, the simultaneous expression of a CAR molecule 
and a "safety switch" suicide gene, such as an inducible caspase 9, would provide an additional safety switch for adoptive T-cell therapy. ${ }^{63}$ Another novel approach to controlling the activity of CAR T-cells is to utilize an intermediate bifunctional molecule as a "switch" to redirect the specificity of CAR T-cells. Kim et al ${ }^{64}$ designed a heterobifunctional folate-FITC conjugate that can not only bind to FRA on cancer cells but also specifically and dose-dependently redirect anti-FITC CAR T-cells to target FRA-expressing cancers. FITC CAR $\mathrm{T}$-cells activation and proliferation were strictly dependent on the presence of both folate-FITC and FRA-positive cells and were dose titratable with the folate-FITC switch. Importantly, administration of free fluorescein molecule could attenuate anti-FITC CAR T-cells activity in the case of toxicity, thereby providing an additional method of controlling CAR T-cells activity. This novel treatment paradigm may ultimately lead to increased safety of FRA CAR T-cells therapy.

\section{Clinical implication and conclusion}

NSCLC is the leading cause of cancer-related death worldwide, and novel treatments are still needed. Restricted distribution of FRA in normal tissues and its high expression in NSCLC allow this antigen to be adapted to a larger panel of therapeutic strategies. The current reports of folate acid conjugates and $\mathrm{mAb}$ targeting FRA are promising, and developing powerful CAR T-cell therapy should be undertaken with caution in clinic. Taken together, this review provides results of encouraging preclinical and clinical studies, which indicates a need for further exploration of various treatment strategies targeting FRA-expressing NSCLC. In conclusion, these FRA-based therapeutic strategies, in sequence with other antitumor therapeutics, hold great promise for improving the prognosis of lung cancer patients in the future.

\section{Acknowledgment}

This work was supported partially by a grant from Shandong Cancer Hospital and Institute (number 09-37), and the Shandong Provincial Natural Science Foundation (number ZR2015YL031).

\section{Disclosure}

The authors declare no conflicts of interest in this work.

\section{References}

1. Siegel R, Naishadham D, Jemal A. Cancer statistics, 2012. CA Cancer J Clin. 2012;62(1):10-29.

2. Goldstraw P, Crowley J, Chansky K, et al; International Association for the Study of Lung Cancer International Staging Committee; Participating Institutions. The IASLC Lung Cancer Staging Project: proposals for the revision of the TNM stage groupings in the forthcoming (seventh) edition of the TNM Classification of malignant tumours. J Thorac Oncol. 2007;2(8):706-714.
3. Siegel R, DeSantis C, Virgo K, et al. Cancer treatment and survivorship statistics, 2012. CA Cancer J Clin. 2012;62(4):220-241.

4. Jäger D, Jäger E, Knuth A. Immune responses to tumour antigens: implications for antigen specific immunotherapy of cancer. JClin Pathol. 2001; 54(9):669-674.

5. Kalli KR, Oberg AL, Keeney GL, et al. Folate receptor alpha as a tumor target in epithelial ovarian cancer. Gynecol Oncol. 2008;108(3):619-626.

6. Hartmann LC, Keeney GL, Lingle WL, et al. Folate receptor overexpression is associated with poor outcome in breast cancer. Int J Cancer. 2007; 121(5):938-942.

7. Bueno R, Appasani K, Mercer H, Lester S, Sugarbaker D. The $\alpha$ folate receptor is highly activated in malignant pleural mesothelioma. J Thorac Cardiovasc Surg. 2001;121(2):225-233.

8. O'Shannessy DJ, Yu G, Smale R, et al. Folate receptor alpha expression in lung cancer: diagnostic and prognostic significance. Oncotarget. 2012; $3(4): 414$.

9. Nunez MI, Behrens C, Woods DM, et al. High expression of folate receptor alpha in lung cancer correlates with adenocarcinoma histology and EGFR mutation. $J$ Thorac Oncol. 2012;7(5):833.

10. Kane MA. The role of folates in squamous cell carcinoma of the head and neck. Cancer Detect Prev. 2005;29(1):46-53.

11. Franklin WA, Waintrub M, Edwards D, et al. New anti-lung-cancer antibody cluster 12 reacts with human folate receptors present on adenocarcinoma. Int J Cancer. 1994;57(S8):89-95.

12. Wu M, Gunning W, Ratnam M. Expression of folate receptor type $\alpha$ in relation to cell type, malignancy, and differentiation in ovary, uterus, and cervix. Cancer Epidemiol Biomarkers Prev. 1999;8(9):775-782.

13. Iwakiri S, Nagai S. Expression status of folate receptor $\alpha$ is significantly correlated with prognosis in non-small-cell lung cancers. Ann Surg Oncol. 2008;15(3):889-899.

14. Kamen BA, Smith AK. A review of folate receptor alpha cycling and 5-methyltetrahydrofolate accumulation with an emphasis on cell models in vitro. Adv Drug Deliv Rev. 2004;56(8):1085-1097.

15. Matherly LH, Goldman ID. Membrane transport of folates. Vitam Horm. 2003;66:403-456.

16. Kelemen LE. The role of folate receptor $\alpha$ in cancer development, progression and treatment: cause, consequence or innocent bystander? Int J Cancer. 2006;119(2):243-250.

17. Toffoli G, Cernigoi C, Russo A, Gallo A, Bagnoli M, Boiocchi M. Overexpression of folate binding protein in ovarian cancers. Int J Cancer. 1997; 74(2):193-198.

18. Toffoli G, Russo A, Gallo A, et al. Expression of folate binding protein as a prognostic factor for response to platinum-containing chemotherapy and survival in human ovarian cancer. Int J Cancer. 1998;79(2): 121-126.

19. Lu Y, Low PS. Immunotherapy of folate receptor-expressing tumors: review of recent advances and future prospects. J Control Release. 2003; 91(1-2):17-29.

20. Weitman SD, Lark RH, Coney LR, et al. Distribution of the folate receptor GP38 in normal and malignant cell lines and tissues. Cancer Res. 1992; 52(12):3396-3401.

21. Lu Y, Sega E, Low PS. Folate receptor-targeted immunotherapy: induction of humoral and cellular immunity against hapten-decorated cancer cells. Int J Cancer. 2005;116(5):710-719.

22. Cagle PT, Zhai QJ, Murphy L, Low PS. Folate receptor in adenocarcinoma and squamous cell carcinoma of the lung: potential target for folate-linked therapeutic agents. Arch Pathol Lab Med. 2013;137(2):241-244.

23. Iwakiri S, Sonobe M, Nagai S, Hirata T, Wada H, Miyahara R. Expression status of folate receptor $\alpha$ is significantly correlated with prognosis in non-small-cell lung cancers. Ann Surg Oncol. 2008;15(3): 889-899.

24. Christoph DC, Asuncion BR, Hassan B, et al. Significance of folate receptor alpha and thymidylate synthase protein expression in patients with non-small cell lung cancer treated with pemetrexed.J Thorac Oncol. 2013;8(1):19.

25. O'Shannessy DJ, Gustavson M, Chandrasekaran LK, Dolled-Filhart M, Somers EB. Prognostic significance of FRA expression in epithelial cancers using AQUA ${ }^{\circledR}$ technology. Biomark Med. 2013;7(6):933-946. 
26. Yu Y, Chen Z, Dong J, et al. Folate receptor-positive circulating tumor cells as a novel diagnostic biomarker in non-small cell lung cancer. Transl Oncol. 2013;6(6):697-702.

27. Allard JE, Risinger JI, Morrison C, et al. Overexpression of folate binding protein is associated with shortened progression-free survival in uterine adenocarcinomas. Gynecol Oncol. 2007;107(1):52-57.

28. Brown Jones M, Neuper C, Clayton A, et al. Rationale for folate receptor alpha targeted therapy in "high risk" endometrial carcinomas. Int J Cancer. 2008;123(7):1699-1703.

29. Zhao X, Li H, Lee RJ. Targeted drug delivery via folate receptors. Expert Opin Drug Deliv. 2008;5(3):309-319.

30. Low PS, Kularatne SA. Folate-targeted therapeutic and imaging agents for cancer. Curr Opin Chem Biol. 2009;13(3):256-262.

31. Leamon CP, Low PS. Delivery of macromolecules into living cells: a method that exploits folate receptor endocytosis. Proc Natl Acad Sci US A. 1991;88(13):5572-5576.

32. Lorusso PM, Edelman MJ, Bever SL, et al. Phase I study of folate conjugate EC145 (Vintafolide) in patients with refractory solid tumors. J Clin Oncol. 2012;30(32):4011-4016.

33. Reddy JA, Dorton R, Westrick E, et al. Preclinical evaluation of EC145, a folate-vinca alkaloid conjugate. Cancer Res. 2007;67(9): 4434-4442.

34. Li J, Sausville EA, Klein PJ, et al. Clinical pharmacokinetics and exposure-toxicity relationship of a folate-Vinca alkaloid conjugate EC145 in cancer patients. J Clin Pharmacol. 2009;49(12):1467-1476.

35. Edelman MJ, Harb WA, Pal SE, et al. Multicenter trial of EC145 in advanced, folate-receptor positive adenocarcinoma of the lung. J Thorac Oncol. 2012;7(10):1618-1621.

36. Leamon CP, Reddy JA, Vlahov IR, et al. Preclinical antitumor activity of a novel folate-targeted dual drug conjugate. Mol Pharm. 2007;4(5): 659-667.

37. Amato R, Engel J, Lu J, Low P, Naveed F. Phase I trial of EC90 (keyhole-limpet hemocyanin fluorescein isothiocyanate conjugate) with GPI-0100 adjuvant followed by EC 17 (folate-fluorescein isothiocyanate conjugate) in patients with metastatic renal cell carcinoma and ovarian cancer. Paper Presented at: American Society of Clinical Oncology (ASCO) 40th Annual Meeting; June 5-8, 2004; New Orleans, LA.

38. Garin-Chesa P, Campbell I, Saigo P, Lewis J Jr, Old L, Rettig W. Trophoblast and ovarian cancer antigen LK26. Sensitivity and specificity in immunopathology and molecular identification as a folate-binding protein. Am J Pathol. 1993;142(2):557.

39. Nicolaides NC, Ebel W, Kline B, et al. Morphogenics as a tool for target discovery and drug development. Ann N Y Acad Sci. 2005;1059(1): 86-96.

40. Kamen B, Smith A. Farletuzumab, an anti-folate receptor $\alpha$ antibody, does not block binding of folate or anti-folates to receptor nor does it alter the potency of anti-folates in vitro. Cancer Chemother Pharmacol. 2012; 70(1):113-120.

41. Ebel W, Routhier EL, Foley B, et al. Preclinical evaluation of MORAb003, a humanized monoclonal antibody antagonizing folate receptoralpha. Cancer Immun. 2007;7(1):6.

42. Wen Y, Graybill WS, Previs RA, et al. Immunotherapy targeting folate receptor induces cell death associated with autophagy in ovarian cancer. Clin Cancer Res. 2015;21(2):448-459.

43. Konner JA, Bell-McGuinn KM, Sabbatini P, et al. Farletuzumab, a humanized monoclonal antibody against folate receptor $\alpha$, in epithelial ovarian cancer: a phase I study. Clin Cancer Res. 2010;16(21):5288-5295.

44. Armstrong DK, White AJ, Weil SC, Phillips M, Coleman RL. Farletuzumab (a monoclonal antibody against folate receptor alpha) in relapsed platinum-sensitive ovarian cancer. Gynecol Oncol. 2013;129(3): 452-458.

45. Sasaki Y, Miwa K, Yamashita K, et al. A phase I study of farletuzumab, a humanized anti-folate receptor $\alpha$ monoclonal antibody, in patients with solid tumors. Invest New Drugs. 2015;33(2):332-340.
46. Pérez-Moreno MA, Galván-Banqueri M, Flores-Moreno S, VillalbaMoreno Á, Cotrina-Luque J, Bautista-Paloma FJ. Systematic review of efficacy and safety of pemetrexed in non-small-cell-lung cancer. Int J Clin Pharm. 2014;36(3):476-487.

47. Grønberg BH, Bremnes RM, Fløtten $\varnothing$, et al. Phase III study by the Norwegian lung cancer study group: pemetrexed plus carboplatin compared with gemcitabine plus carboplatin as first-line chemotherapy in advanced Non-small-cell lung cancer. J Clin Oncol. 2009;27(19): 3217-3224.

48. Scagliotti GV, Parikh P, von Pawel J, et al. Phase III study comparing cisplatin plus gemcitabine with cisplatin plus pemetrexed in chemotherapy-naive patients with advanced-stage non-small-cell lung cancer. J Clin Oncol. 2008;26(21):3543-3551.

49. Ciuleanu T, Brodowicz T, Zielinski C, et al. Maintenance pemetrexed plus best supportive care versus placebo plus best supportive care for non-small-cell lung cancer: a randomised, double-blind, phase 3 study. Lancet. 2009;374(9699):1432-1440.

50. Paz-Ares L, de Marinis F, Dediu M, et al. Maintenance therapy with pemetrexed plus best supportive care versus placebo plus best supportive care after induction therapy with pemetrexed plus cisplatin for advanced non-squamous non-small-cell lung cancer (PARAMOUNT): a double-blind, phase 3, randomised controlled trial. Lancet Oncol. 2012; 13(3):247-255.

51. Wang J, Wang X. Beyond chemotherapy and targeted therapy: adoptive cellular therapy in non-small cell lung cancer. Mol Biol Rep. 2014; 41(9):6317-6323.

52. June $\mathrm{CH}$. Adoptive $\mathrm{T}$ cell therapy for cancer in the clinic. J Clin Invest. 2007;117(6):1466.

53. Shi H, Liu L, Wang Z. Improving the efficacy and safety of engineered T cell therapy for cancer. Cancer Lett. 2013;328(2):191-197.

54. Song DG, Ye Q, Carpenito C, et al. In vivo persistence, tumor localization, and antitumor activity of CAR-engineered $\mathrm{T}$ cells is enhanced by costimulatory signaling through CD137 (4-1BB). Cancer Res. 2011; 71(13):4617-4627.

55. Song D-G, Ye Q, Poussin M, Harms GM, Figini M, Powell DJ. CD27 costimulation augments the survival and antitumor activity of redirected human T cells in vivo. Blood. 2012;119(3):696-706.

56. Sadelain M, Brentjens R, Rivière I. The basic principles of chimeric antigen receptor design. Cancer Discov. 2013;3(4):388-398.

57. Liu L, Sun M, Wang Z. Adoptive T-cell therapy of B-cell malignancies: conventional and physiological chimeric antigen receptors. Cancer Lett. 2012;316(1):1-5.

58. Kershaw MH, Westwood JA, Parker LL, et al. A phase I study on adoptive immunotherapy using gene-modified $\mathrm{T}$ cells for ovarian cancer. Clin Cancer Res. 2006;12(20):6106-6115.

59. Morgan RA, Yang JC, Kitano M, Dudley ME, Laurencot CM, Rosenberg SA. Case report of a serious adverse event following the administration of $\mathrm{T}$ cells transduced with a chimeric antigen receptor recognizing ERBB2. Mol Ther. 2010;18(4):843-851.

60. Heslop HE. Safer cars. Mol Ther. 2010;18(4):661.

61. Zhao Y, Moon E, Carpenito C, et al. Multiple injections of electroporated autologous $\mathrm{T}$ cells expressing a chimeric antigen receptor mediate regression of human disseminated tumor. Cancer Res. 2010;70(22): 9053-9061.

62. Beatty GL, Haas AR, Maus MV, et al. Mesothelin-specific chimeric antigen receptor mRNA-engineered $\mathrm{T}$ cells induce antitumor activity in solid malignancies. Cancer Immunol Res. 2014;2(2):112-120.

63. Straathof KC, Pulè MA, Yotnda $\mathrm{P}$, et al. An inducible caspase 9 safety switch for T-cell therapy. Blood. 2005;105(11):4247-4254.

64. Kim MS, Ma JS, Yun H, et al. Redirection of genetically engineered CAR-T cells using bifunctional small molecules. J Am Chem Soc. 2015; 137(8):2832-2835. 


\section{Publish your work in this journal}

Drug Design, Development and Therapy is an international, peerreviewed open-access journal that spans the spectrum of drug design and development through to clinical applications. Clinical outcomes, patient safety, and programs for the development and effective, safe, and sustained use of medicines are a feature of the journal, which

has also been accepted for indexing on PubMed Central. The manuscript management system is completely online and includes a very quick and fair peer-review system, which is all easy to use. Visit http://www.dovepress.com/testimonials.php to read real quotes from published authors.

Submit your manuscript here: http://www.dovepress.com/drug-design-development-and-therapy-journal 